\title{
Measuring PhD Students' Well-being: Are we Seeing the Whole Picture?
}

\author{
Hannah Scott \\ Flinders University, Adelaide, Australia \\ Melanie K. T. Takarangi \\ Flinders University, Adelaide, Australia
}

\begin{abstract}
The well-being of $\mathrm{PhD}$ students has become of interest recently after reports of high levels of psychological distress and mental illness amongst these students. To measure well-being among PhD students, some studies have used instruments that measure constructs related to well-being, most commonly psychological distress, whilst other aspects of well-being are overlooked. This review used a systematic approach to investigate how well-being is conceptualised in this literature and to identify and evaluate the quality of instruments used to measure $\mathrm{PhD}$ students' well-being. The search strategy identified 19 articles for inclusion. Most studies measured constructs related to well-being, mainly mental illness symptoms, or constructs associated with subjective well-being and self-determination theory. Few studies measured aspects of psychological well-being. Furthermore, few questionnaires were validated for a $\mathrm{PhD}$ student population and many measures had no validity or reliability information available. Future research should be conducted using good quality measures to assess overlooked aspects of the six-factor model of well-being and provide a comprehensive assessment of well-being in this student group.
\end{abstract}

Keywords: Well-being; mental health; PhD students; doctorate students; psychological well-being

\section{Introduction}

Both the academic literature and popular media have highlighted growing concerns about the well-being of higher education students (Anonymous Academic, 2014; Cvetkovski, Reavley, \& Jorm, 2012; Eisenberg, Hunt, \& Speer, 2013; Stecker, 2004). To date, however, much of the research on university students' well-being has focused on the undergraduate student group, or undergraduate and postgraduate students combined. Yet there are several factors-likely harmful to well-being - that are arguably unique to the postgraduate experience. Students completing a doctoral degree (hereafter, referred to as "PhD students") report struggling with feelings of social isolation, lack of motivation, and challenges with supervisors and the academic environment (Castelló, Pardo, Sala-Bubaré, \& Suñe-Soler, 2017; Janta, Lugosi, \& Brown, 2014; Lovitts, 2002; Sverdlik \& Hall, 2019). Until recently, attention to such factors in the literature has been limited; research has tended to focus on how these factors predict completion and attrition rates (Lovitts \& Nelson, 2000; Schmidt \& Hansson, 2018; Sverdlik, Hall, McAlpine, \& Hubbard, 2018). Further, although extant studies have measured some aspects of mental health-most commonly psychological distress - other aspects are not well-studied, including psychological well-being. To draw clear conclusions and implications from these findings, we need to ensure that well-being is clearly and consistently conceptualised, that it is assessed comprehensively, and that it is measured using valid and reliable tools. To this end, our current review focuses on how existing research has conceptualised and measured the well-being of $\mathrm{PhD}$ students.

This work is licensed under a Creative Commons Attribution 4.0 International Licence. As an open access journal, articles are free to use with proper attribution. ISSN: 2205-0795 
Well-being is a broad construct that concerns how and why our lives have meaning, and is an integral component of mental health (World Health Organisation, 2014). Mental health is not simply the absence of a mental illness, such as depression or anxiety, but rather the extent to which a person is emotionally, psychologically and socially well. The dual continua model of mental health and mental illness (Westerhof \& Keyes, 2010) considers these two constructs as related, with low levels of wellbeing potentially manifesting as a mental illness. Yet, these two constructs are distinct - meaning that both well-being and mental illness need to be assessed to understand a person's mental health. According to Carol Ryff's Six-Factor Model, psychological well-being encompasses purpose in life, autonomy, personal growth, environmental mastery, positive relationships, and self-acceptance (Ryff, 1989; Ryff \& Keyes, 1995). Other theories of well-being include Deiner's tripartite model of subjective well-being, which relates to positive and negative affect and a person's sense of satisfaction with their life (Diener, 1984; 2000), self-determination theory which relates to competence, relatedness and autonomy (Ryan \& Deci, 2000), and the PERMA model (positive emotions, engagement, relationships, meaning and achievement - Seligman, 2011). In this review, we will investigate how the well-being of $\mathrm{PhD}$ students is conceptualised and studied under these specific models of well-being.

With high levels of well-being theoretically required to achieve a $\mathrm{PhD}$ degree, it is no surprise that low levels of well-being can have a substantial impact on $\mathrm{PhD}$ students' degree progress, professional development, research productivity and personal lives (Schmidt \& Hansson, 2018). These problems, in turn, have administrative and financial implications for universities. First, we know that poor mental health — which is linked to low levels of well-being - is associated with increased dropout risk, and candidature interruptions (Anttila, Lindblom-Ylänne, Lonka, \& Pyhältö, 2015; Ives \& Rowley, 2005; Stubb, Pyhältö, \& Lonka, 2011). Second, drawing upon research with academics, we know that poor mental health leads to reduced research output (Ryan $\&$ Deci, 2000), and thus we would expect to see a similar pattern with PhD students. Given that PhD students' research make a sizeable contribution to overall research output from universities (Larivière, 2012; Pearson, Evans, \& Macauley, 2008), low levels of well-being amongst a $\mathrm{PhD}$ cohort could substantially reduce the quality and quantity of a university's research outputs. Third, it is worth considering the flow-on effects of lost productivity and poor progress that arise in concert with low levels of well-being. If a PhD student is not satisfactorily meeting the expectations of the degree, then it may be unlikely that they would engage with additional activities to enhance their learning and development, such as skill development workshops. This lack of engagement is problematic not only because these 'additional' activities are becoming incorporated into the expectations of the PhD candidature (Horta \& Santos, 2016; Park, 2005), but also because it feeds back into student performance in producing research output. Finally, of even greater concern, low levels of well-being can significantly impact doctoral students' personal lives. Psychological well-being is negatively associated with symptoms of mental illness, including depression (Ryff, 1989). Considering that rates of depression and anxiety are high amongst the doctoral student cohort (Levecque, Anseel, De Beuckelaer, Van der Heyden, \& Gisle, 2017), it is important to understand the well-being of this student group.

Universities have a duty of care to their students. Indeed, administrators and educators have a responsibility to create and maintain — potentially via changes in policy and practice — an environment that supports PhD students' well-being. Achieving this outcome requires strong empirical support from research conducted with high quality measures. With a view to providing that support and suggesting future research directions that could bolster it further, here we systematically reviewed studies that have measured PhD students' well-being. Our aims were twofold: to investigate how well-being has been conceptualised in the literature to date and to assess the quality of the well-being measures.

\section{Method}

\section{Search Strategies}

We conducted searches in PsychINFO, ProQuest, and SCOPUS databases on $19^{\text {th }}$ June 2019. The database search strategies included title/abstract keywords and relevant subject headings under two categories: PhD students ('doctoral student', 'post graduate student', etc.) and well-being ('well-being', 'autonomy', 'mental health', etc.). ${ }^{1}$ Search results were restricted to articles published in English. We also screened the reference lists of articles identified as eligible during the database search and consulted each other to identify articles not captured via other searches. These additional search strategies were completed by $22^{\text {nd }}$ June 2019 .

\footnotetext{
${ }^{1}$ See the Supplementary Materials (Appendix A) for the specific search strategies for each database.
} 


\section{Article Selection}

We imported our search results into Endnote X8.2 for de-duplication and screening purposes. The primary author screened the remaining articles according to the eligibility criteria outlined in Table 1 . We designed these selection criteria to include articles that assessed at least one aspect of well-being in $\mathrm{PhD}$ students. Titles and abstracts were screened first, and then the full texts of the remaining articles.

Table 1

Article eligibility criteria

\begin{tabular}{l}
\hline Article Criteria \\
\hline Original, peer-reviewed articles \\
Written in English \\
Full text available \\
\hline Measurement Criteria \\
\hline Included a quantitative measure of an aspect of well-being. \\
\hline Sample Criteria \\
\hline Presented findings that pertained exclusively to PhD students. \\
$\qquad \quad$ Included students enrolled in professional doctorate programs. \\
$\quad$ otheluded articles that presented findings that combined PhD students with \\
\hline
\end{tabular}

\section{Data Extraction}

The primary author extracted key data fields. These fields included relevant article information (year, location), sample characteristics (location, sample size), and measurement information (instrument name, validity and reliability information). Table 2 in the Results section contains the extracted data about the article and sample, and Table 3 (Supplementary Materials) lists the measurement information.

\section{Results}

The PRISMA flow diagram in Figure 1 details the study selection process that resulted in 19 articles meeting the eligibility criteria for inclusion in this review.

\section{Figure 1}

PRISMA flowchart detailing the study selection process

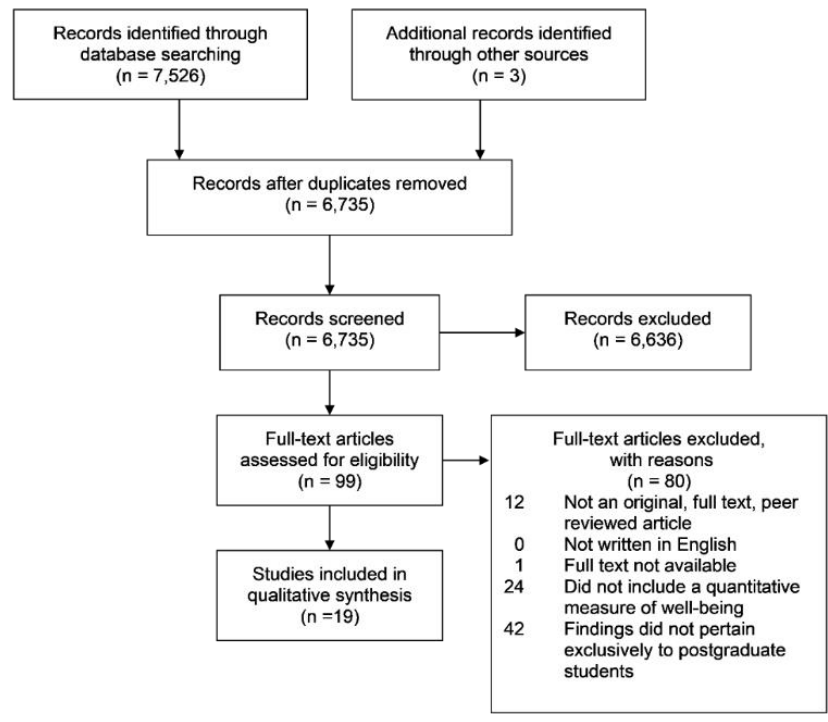


As shown in Table 2, most eligible articles were published in the previous five years (14/19 articles) indicating that this is a growing area of research. Studies were mostly conducted in Europe (13/19 studies), the United States (6/19 studies), and Canada (5/19 studies). Two studies used the same longitudinal data set collected in Belgium (De Clercq et al., 2019; Levecque et al., 2017) and four studies used a Finnish data set (Lonka, Ketonen, Vekkaila, Cerrato Lara, \& Pyhältö, 2019; Pyhältö \& Keskinen, 2012; Stubb, Pyhalto, \& Lonka, 2012; Stubb et al., 2011). Two studies also analysed an international data set, with respondents located primarily in Canada and the United States (Devine \& Hunter, 2017; Hunter \& Devine, 2016). Sample sizes ranged from 119 to 5,980 .

Table 2

Study characteristics of the eligible articles

\begin{tabular}{llll}
\hline Author & Year & Location & $\begin{array}{l}\text { Sample } \\
\text { Size }\end{array}$ \\
\hline Anttila et al. & 2015 & Finland & 163 \\
\hline Caesens et al. & 2014 & Belgium & 343 \\
\hline De Clercq et al. & 2019 & Belgium & 446 \\
\hline Devine \& Hunter & 2017 & Canada, United States, United Kingdom, Australia, New Zealand, & 183 \\
& & Norway, France, South Africa & 186 \\
\hline Hunter \& Devine & 2016 & Canada, United States, United Kingdom, Australia, New Zealand, & 18 \\
\hline Juniper et al. & & Norway, France, and South Africa & 1202 \\
\hline Levecque et al. & 2012 & United Kingdom & 3659 \\
\hline Lipson et al. & 2017 & Belgium & 5980 \\
\hline Lonka et al. & 2016 & United States & 664 \\
\hline Lynch et al. & 2019 & Finland & 120 \\
\hline Marais et al. & 2018 & Russia & 846 \\
\hline Moate et al. & 2018 & France & 528 \\
\hline Pychyl \& Little & 2019 & United States & 200 \\
\hline Pyhältö \& Keskinen & 1998 & Canada & 669 \\
\hline Rummell & 2012 & Finland & 119 \\
\hline Stubb et al. & 2015 & United States and Canada & 669 \\
\hline Stubb et al. & 2011 & Finland & 669 \\
\hline Sverdlik \& Hall & 2012 & Finland & 3004 \\
\hline Zahniser et al. & 2019 & 54 countries, mainly United States and Canada & 358 \\
\hline
\end{tabular}

\section{Constructs Assessed in the Eligible Articles}

Figure 2 presents the frequency with which broad constructs relevant to well-being were explored in the eligible articles. As shown, the most common measures were stress (10 instances) and mental health (depression and anxiety; 14 instances). For instance, Levecque et al. (2017) examined the prevalence of psychiatric disorder symptoms in a large sample of PhD students in Belgium, inferring students' risk of having or developing a disorder, particularly depression. Similarly, Lipson, Zhou, Wagner, Beck, and Eisenberg (2016) studied depression, anxiety, suicidal ideation, and self-injury. Four studies described instances of exhaustion in PhD students (Lonka et al., 2019; Pyhältö \& Keskinen, 2012; Stubb et al., 2012; Stubb et al., 2011). Relatedly, two studies administered assessments of both mental health and well-being. Sverdlik and Hall (2019) described the psychological health of PhD students, focussing on depression, strain, and self-determined motivation, and Marais, Shankland, Haag, Fiault, and Juniper (2018) administered assessments of depression and anxiety alongside PhD student-specific measures of psychological well-being. It is clear that there is a strong focus on mental illness and psychological distress in this literature. 


\section{Figure 2}

The number of instances that eligible articles explored broad aspects relevant to well-being

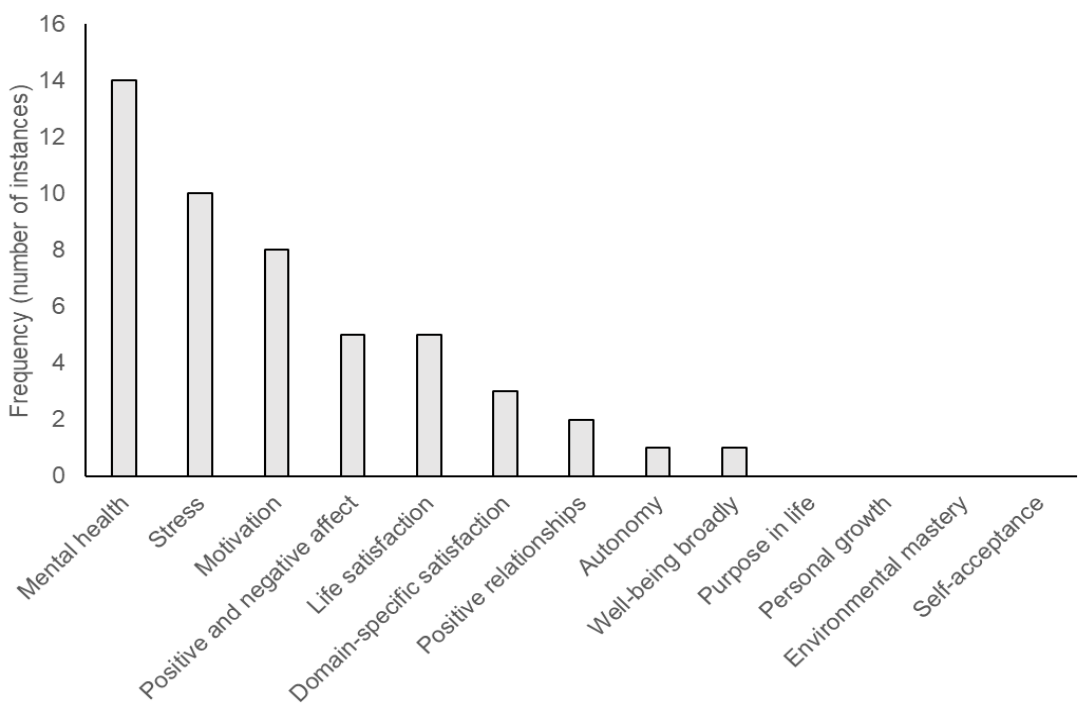

Of those studies that measured well-being, many studies explored factors of well-being relating to Deiner's tripartite model of subjective well-being, including five studies that measured positive and/or negative affect (Devine \& Hunter, 2017; Hunter \& Devine, 2016; Moate, Gnilka, West, \& Rice, 2019; Pychyl \& Little, 1998; Zahniser, Rupert, \& Dorociak, 2017). Four studies also investigated overall life satisfaction (Moate et al., 2019; Pychyl \& Little, 1998; Rummell, 2015; Zahniser et al., 2017), while three studies measured domain-specific satisfaction such as with academic life and their job as a PhD student (Caesens, Stinglhamber, \& Luypaert, 2014; Juniper, Walsh, Richardson, \& Morley, 2012; Marais et al., 2018). Similarly, eight studies investigated motivation, both intrinsic and extrinsic motivation, in line with well-being as theorised under self-determination theory (Anttila et al., 2015; Lonka et al., 2019; Lynch, Salikhova, \& Salikhova, 2018; Marais et al., 2018; Pyhältö \& Keskinen, 2012; Stubb et al., 2012; Stubb et al., 2011; Sverdlik \& Hall, 2019).

Three of the eligible articles measured factors from the six-factor model of psychological well-being. Social support - assessed as coming either from family and friends, or from the student's supervisory team and colleagues (De Clercq et al., 2019; Devine \& Hunter, 2017) - may act as a proxy for the positive relationships factor of the model. Lynch et al. (2018) also investigated another factor from this model: autonomy. However, none of the eligible articles assessed other factors from this model purpose in life, personal growth, environmental mastery, and self-acceptance.

\section{Instrument Evaluation}

Table $3^{2}$ presents the descriptions of each well-being instrument administered in the eligible articles. We extracted this information from the eligible articles and incorporated missing information from other sources, where possible. Five measures were administered across multiple studies: the Perceived Stress Scale (Caesens et al., 2014; Moate et al., 2019; Rummell, 2015; Sverdlik \& Hall, 2019; Zahniser et al., 2017), the MED NORD (Anttila et al., 2015; Lonka et al., 2019; Pyhältö \& Keskinen, 2012; Stubb et al., 2012; Stubb et al., 2011), the Satisfaction with Life Scale (Moate et al., 2019; Pychyl \& Little, 1998), the Juniper PhD student well-being scale (Juniper et al., 2012; Marais et al., 2018), and the Motivation for a PhD scale (Marais et al., 2018; Sverdlik \& Hall, 2019).

Some measures have robust empirical evidence available to support their validity and reliability, but are typically measures of mental illness, not well-being. For example, Levecque et al. (2017) administered the General Health Questionnaire (GHQ) to examine symptoms of psychological disorders, particularly depression, in $\mathrm{PhD}$ students. This questionnaire has undergone extensive validation in many populations, including university students and young Australians (Winefield, Goldney, Winefield, \& Tiggemann, 1989; Yaghubi, Karimi, Omidi, Barouti, \& Abedi, 2012). Similarly, Lipson et al. (2016) assessed depression

${ }^{2}$ See the Supplementary Materials (Appendix A). 
and anxiety symptoms using the Patient Health Questionnaire. This questionnaire is commonly used in research to screen for both major and subthreshold depression (Martin, Rief, Klaiberg, \& Braehler, 2006; Yoon et al., 2014). Although these are both high quality questionnaires, they measure severity of mental illness, specifically depression, rather than well-being.

Some studies included measures - validated in either the general or a student population - for assessing life satisfaction and stress (Pavot \& Diener, 2009). Moate et al. (2019) and Pychyl and Little (1998) administered the Satisfaction with Life scale (Diener, Emmons, Larsen, \& Griffin, 1985). This questionnaire has high test-retest reliability, strong correlations with similar measures, and discriminates from emotional well-being in many populations (Lucas, Diener, \& Suh, 1996). Five studies used another measure developed with medical students to assess well-being called the MED NORD questionnaire (Anttila et al., 2015; Lonka et al., 2019; Pyhältö \& Keskinen, 2012; Stubb et al., 2012; Stubb et al., 2011). This tool was developed and validated to assess well-being, which the authors conceptualised as stress, exhaustion, and anxiety, as well as other constructs like interest towards learning (Lonka et al., 2019).

Three measures administered in the eligible articles specifically assessed factors from the model of psychological well-being. Lynch et al. (2018) administered the Index of Autonomous Functioning: a measure of trait autonomy validated in the general population. This measure showed high reliability and predictive ability of well-being (Weinstein, Przybylski, \& Ryan, 2012). Furthermore, measures of social support were administered in two eligible articles relating to the positive relationships factor of the six-factor model of psychological well-being. Devine and Hunter (2017) administered a scale developed in Oldham and Cummings (1996) that was designed to measure how supervision influences performance in manufacturing employees, which may not translate to supervisory support for a $\mathrm{PhD}$ student and is currently not validated for use in this particular group. Similarly, De Clercq et al. (2019) constructed items based on previous research to measure instrumental and affective social support. Whilst the supervisor and academic peer support subscales showed acceptable internal consistency $(\alpha=.89$ and .86 , respectively), the relative support subscale did not $(\alpha=.68)$, and the validity of the questionnaire is currently unknown. No study measured the following factors from the model of psychological well-being: purpose in life, personal growth, environmental mastery, and self-acceptance.

Two studies assessed factors from the psychological well-being model using a questionnaire developed specifically for $\mathrm{PhD}$ students (Juniper et al., 2012; Marais et al., 2018). Juniper et al. (2012) developed this questionnaire in conjunction with PhD students by identifying questions that could assess domains that affect $\mathrm{PhD}$ students' well-being. The final version of the questionnaire assesses seven domains that both define and impact well-being: development, facilities, home and health, research, social, supervisor, and the university (Juniper et al., 2012). This questionnaire has shown high internal consistency but evidence regarding validity and other forms of reliability are yet to be published. Similarly, Marais et al. (2018) also administered the Motivation for a PhD scale: a 15-item questionnaire designed to assess $\mathrm{PhD}$ students' intrinsic, integrated, identified, introjected, and external motivation towards their $\mathrm{PhD}$ studies, which relates to motivation as conceptualised under self-determination theory. Litalien, Guay, and Morin (2015) validated this questionnaire in two samples of PhD students. The authors showed that the questionnaire had high internal consistency and that scores correlated highly with PhD-specific outcomes, including satisfaction, performance, and intention to withdraw from the degree (Litalien et al., 2015).

The authors of five eligible articles developed new measures of well-being or mental illness (De Clerq et al., 2019; Juniper et al., 2012; Lipson et al., 2016; Rummell, 2015; Sverdlik \& Hall, 2019). Rummell (2015) assessed depression and anxiety symptoms. Whilst these items were based upon standardised diagnostic criteria, the questionnaire itself has not been validated for screening for depression or anxiety. Nonetheless, internal consistency was high for the three factors of anxiety, depression and total psychological stress, $\alpha=.81-.87$ (Rummell, 2015). Similarly, Lipson et al. (2016) developed single-item measures to assess suicidal ideation and self-injury behaviours. The construct validity of these items is currently unknown.

\section{Discussion}

This review investigated how the well-being of PhD students is conceptualised and measured in the literature. We found that the eligible articles primarily assessed mental illness symptoms and stress (e.g. Levecque et al., 2017; Pyhältö \& Keskinen, 2012; Stubb et al., 2012; Sverdlik \& Hall, 2019) These studies have begun to shed light on what is a concerning picture of PhD students' mental health. Further investigation using valid and reliable measures is warranted to identify how to address concerns about mental health in this student group.

Shedding more light on the picture of PhD students' mental health are studies that have measured an aspect of well-being. Some of the eligible articles investigated aspects of well-being described under self-determination theory (e.g. Anttila et al., 
2015; Lonka et al., 2019; Marais et al., 2018; Stubb et al., 2012; Sverdlik \& Hall, 2019) and Deiner's model of subjective wellbeing (e.g. Devine \& Hunter, 2017; Hunter \& Devine, 2016; Pychyl \& Little, 1998; Rummell, 2015). However, there are notable gaps in this literature, particularly in the assessment of factors from the six-factor model of psychological well-being. Three articles measured factors from the six-factor model, namely social support (De Clercq et al., 2019; Devine \& Hunter, 2017) and autonomy (Lynch et al., 2018). Purpose in life, personal growth, environmental mastery, and self-acceptance were not assessed in the eligible articles. Considering the substantial evidence behind this theoretical framework, this is a significant gap in the literature. What's more, undertaking a $\mathrm{PhD}$ can be viewed as the ultimate attempt at environmental mastery of a particular domain in higher education; it may require a high degree of autonomy coupled with positive relationships for academic and personal support (De Clercq et al., 2019), self-acceptance to avoid imposter syndrome, and positive outcomes include personal growth and fulfilment of a life goal (purpose in life). Therefore, the six-factor model of psychological wellbeing may provide a useful theoretical framework to understand well-being in the doctoral degree context, and future studies should specifically target and measure factors from this model with $\mathrm{PhD}$ students.

In the articles we reviewed, many well-being measures did not have validity and reliability information available. Those measures with more robust empirical evidence to support their validity were measures of mental illness or psychological distress, including the General Health Questionnaire and Patient Health Questionnaire (Levecque et al., 2017; Lipson et al., 2016), or measures of aspects of well-being outside of the six-factor model, such as the Satisfaction with Life scale (Moate et al., 2019; Pychyl \& Little, 1998). Juniper et al. (2012) and Marais et al. (2018) administered measures of well-being specifically for PhD students, but little is known about their validity. Valid and reliable instruments that measure aspects of the six-factor model of psychological well-being are missing from this literature and should be utilised in future research studies.

Notwithstanding inconsistencies across the measures used, and missing information about measure quality, the available evidence about $\mathrm{PhD}$ students' well-being presents a bleak picture for higher education. $\mathrm{PhD}$ students report a higher prevalence of mental illness symptoms than highly educated individuals in the general population, highly educated employed individuals, and other higher education students (Levecque et al., 2017). Research is increasingly linking these poor mental health outcomes to the university environment. Whilst some PhD students feel empowered in the academic environment, others report feeling burdened by academia (Stubb et al., 2011). This pattern should signal to universities an urgent need to act to address PhD students' well-being.

This bleak picture of doctoral education has important implications for universities. Suggestions to improve PhD students' well-being have included providing student-centred targeted interventions to develop students' resilience and autonomy (Kearns, Gardiner, \& Marshall, 2008; Serrão \& Alves, 2019). However, it is difficult to know if and to what extent these aspects of well-being need intervention when our measures are not capturing these aspects thoroughly in this student group. For instance, consider a situation where PhD students' scores on a measure indicated that they had low levels of well-being. If we knew that purpose in life was the prominent issue for $\mathrm{PhD}$ students as assessed on this measure, then education about project planning to ensure timely completion of degree requirements and access to tailored advice about career trajectories may all help $\mathrm{PhD}$ students to achieve life goals, thereby improving well-being. Yet, if a lack of positive relationships with others was the primary underlying reason for the low levels of well-being on this measure, then these interventions would presumably have limited effectiveness. Furthermore, low levels of well-being may result from issues across a range of factors of well-being, rather than from one prominent issue - again, requiring targeted interventions to address appropriately. For universities to address PhD students' well-being appropriately, the comprehensive measurement of well-being is needed to inform interventions and policy changes.

Furthermore, change may need to occur at the institutional rather than individual level to improve PhD students' well-being. For instance, if $\mathrm{PhD}$ students in a particular university felt that they lacked academic support, potentially as assessed using domain-specific well-being questionnaires (De Clercq et al., 2019; Lynch et al., 2018), then the university may need to promote positive relationships between students and their supervisors, institution-wide. The university may need to provide clear guidelines for student/supervisor expectations and additional training to both student and supervisors, potentially about conflict resolution and relationship boundaries. In sum, a wide variety of useful interventions and policy changes may result from comprehensively assessing $\mathrm{PhD}$ students' well-being.

Of course, our review has important limitations. We only included studies that measured well-being quantitatively. Qualitative measurement was beyond the scope of the review, but these studies may offer additional insight into PhD students' well-being (Hiltz-Hymes, Spicer, Hardy, Waddell, \& Hatcher, 2015; Schmidt \& Umans, 2014). Furthermore, only peer-reviewed journal 
articles were eligible and dissertations and white papers were excluded; again, these sources would shed additional light on this topic (Zahl, 2013).

\section{Conclusion}

Using a systematic approach, this review identified studies that have measured various aspects of PhD students' well-being and offered a critique of the well-being measures. Gaps exist in the conceptualisation of well-being in this student group, particularly relating to factors of the six-factor model of psychological well-being: environmental mastery, personal growth, purpose in life, and self-acceptance, most notably. Comprehensive assessment of PhD students' well-being using valid and reliable measures will enable universities to initiate tailored interventions and policy changes to improve PhD students' well-being on an individual or institutional level, enhancing the student's life, learning and development.

\section{References}

Anonymous Academic. (2014, 1 March). There is a culture of acceptance around mental health issues in academia. The Guardian. Retrieved from https://www.theguardian.com/higher-education-network/blog/2014/mar/01/mental-healthissue-phd-research-university

Anttila, H., Lindblom-Ylänne, S., Lonka, K., \& Pyhältö, K. (2015). The Added Value of a PhD in Medicine - PhD Students' Perceptions of Acquired Competences. International Journal of Higher Education, 4(2). https://doi.org/10.5430/ijhe.v4n2p172

Belmont, M., Skinner, E., Wellborn, J., \& Connell, J. (1988). Teacher as social context: A measure of student perceptions of teacher provision of involvement, structure, and autonomy support. (Vol. 102). Tech. rep.

Bhullar, N., Hine, D. W., \& Phillips, W. J. (2014). Profiles of psychological well-being in a sample of Australian university students. International Journal of Psychology, 49(4), 288-294. https://doi.org/10.1002/ijop.12022

Black, A. E., \& Deci, E. L. (2000). The effects of instructors' autonomy support and students' autonomous motivation on learning organic chemistry: A self-determination theory perspective. Science Education, 84(6), 740-756. https://doi.org/10.1002/1098-237X(200011)84:6\%3C740::AID-SCE4\%3E3.0.CO;2-3

Caesens, G., Stinglhamber, F., \& Luypaert, G. (2014). The impact of work engagement and workaholism on well-being: The role of work-related social support. The Career Development International, 19(7), 813-835.

http://dx.doi.org/10.1108/CDI-09-2013-0114

Castelló, M., Pardo, M., Sala-Bubaré, A., \& Suñe-Soler, N. (2017). Why do students consider dropping out of doctoral degrees? Institutional and personal factors. Higher Education, 74(6), 1053-1068. https://doi.org/10.1007/s10734-0160106-9

Cohen, S. (1988). Perceived stress in a probability sample of the United States. In S. Spacapan \& S. Oskamp (Eds.), The Social Psychology of Health (pp. 31-67). Sage.

Cohen, S., Kamarck, T., \& Mermelstein, R. (1983). A global measure of perceived stress. Journal of Health and Social Behavior, 24(4), 385-396. https://psycnet.apa.org/doi/10.2307/2136404

Cvetkovski, S., Reavley, N. J., \& Jorm, A. F. (2012). The prevalence and correlates of psychological distress in Australian tertiary students compared to their community peers. Australian \& New Zealand Journal Psychiatry, 46(5), $457-467$. https://doi.org/10.1177/0004867411435290

De Clercq, M., Devos, C., Azzi, A., Frenay, M., Klein, O., \& Galand, B. (2019). I need somebody to lean on: The effect of peer, relative, and supervisor support on emotions, perceived progress, and persistence in different stages of doctoral advancement. Swiss Journal of Psychology. https://psycnet.apa.org/doi/10.1024/1421-0185/a000224

Devine, K., \& Hunter, K. H. (2017). PhD student emotional exhaustion: The role of supportive supervision and selfpresentation behaviours. Innovations in Education and Teaching International, 54(4), 335-344. http://dx.doi.org/10.1080/14703297.2016.1174143

Diener, E. (1984). Subjective well-being. Psychological Bulletin, 95(3), 542-575. https://psycnet.apa.org/doi/10.1037/00332909.95.3.542

Diener, E. (2000). Subjective well-being: The science of happiness and a proposal for a national index. American Psychologist, 55(1), 34-43. https://psycnet.apa.org/doi/10.1037/0003-066X.55.1.34

Diener, E., \& Emmons, R. A. (1984). The independence of positive and negative affect. Journal of Personality and Social Psychology, 47(5), 1105. https://psycnet.apa.org/doi/10.1037/0022-3514.47.5.1105

Diener, E., Emmons, R. A., Larsen, R. J., \& Griffin, S. (1985). The satisfaction with life scale. Journal of Personality Assessment, 49(1), 71-75. https://doi.org/10.1207/s15327752jpa4901_13 
Diener, E., Wirtz, D., Tov, W., Kim-Prieto, C., Choi, D.-w., Oishi, S., \& Biswas-Diener, R. (2010). New well-being measures: Short scales to assess flourishing and positive and negative feelings. Social Indicators Research, 97(2), 143156. https://doi.org/10.1007/s11205-009-9493-y

Dupont, S., Galand, B., \& Nils, F. (2015). The impact of different sources of social support on academic performance: Intervening factors and mediated pathways in the case of master's thesis. Revue Européenne de Psychologie Appliquée/European Review of Applied Psychology, 65(5), 227-237. https://psycnet.apa.org/doi/10.1016/j.erap.2015.08.003

Eisenberg, D., Hunt, J., \& Speer, N. (2013). Mental health in American colleges and universities: variation across student subgroups and across campuses. The Journal of Nervous and Mental Disease, 201(1), 60-67. https://doi.org/10.1097/NMD.0b013e31827ab077

Eisenberger, R., Cummings, J., Armeli, S., \& Lynch, P. (1997). Perceived organizational support, discretionary treatment, and job satisfaction. Journal of Applied Psychology, 82(5), 812. https://psycnet.apa.org/doi/10.1037/0021-9010.82.5.812

Goldberg, D., \& Williams, P. (1988). A user's guide to the General Health Questionnaire. NFER-Nelson.

Hiltz-Hymes, C. E., Spicer, S., Hardy, E. A., Waddell, M., \& Hatcher, S. L. (2015). Midcourse corrections and life satisfaction in a sample of mid-career doctoral students. The Qualitative Report, 20(10), 1709-1722. Retrieved from https://nsuworks.nova.edu/tqr/vol20/iss10/12/

Horta, H., \& Santos, J. M. (2016). The impact of publishing during PhD studies on career research publication, visibility, and collaborations. Research in Higher Education, 57(1), 28-50. https://doi.org/10.1007/s11162-015-9380-0

Hunter, K. H., \& Devine, K. (2016). Doctoral students' emotional exhaustion and intentions to leave academia. International Journal of Doctoral Studies, 11, 35-61. https://doi.org/10.28945/3396

Ives, G., \& Rowley, G. (2005). Supervisor selection or allocation and continuity of supervision: Ph.D. students' progress and outcomes. Studies in Higher Education, 30(5), 535-555. https://doi.org/10.1080/03075070500249161

Janta, H., Lugosi, P., \& Brown, L. (2014). Coping with loneliness: A netnographic study of doctoral students. Journal of Further and Higher Education, 38(4), 553-571. https://doi.org/10.1080/0309877X.2012.726972

Juniper, B., Walsh, E., Richardson, A., \& Morley, B. (2012). A new approach to evaluating the well-being of PhD research students. Assessment and Evaluation in Higher Education, 37(5), 563-576. https://doi.org/10.1080/02602938.2011.555816

Kearns, H., Gardiner, M., \& Marshall, K. (2008). Innovation in PhD completion: The hardy shall succeed (and be happy!). Higher Education Research \& Development, 27(1), 77-89. https://doi.org/10.1080/07294360701658781

Kohn, P. M., Lafreniere, K., \& Gurevich, M. (1990). The inventory of college students' recent life experiences: A decontaminated hassles scale for a special population. Journal of Behavioral Medicine, 13(6), 619-630. https://doi.org/10.1007/BF00844738

Kroenke, K., Spitzer, R. L., \& Williams, J. B. (2001). The PHQ-9: Validity of a brief depression severity measure. Journal of General Internal Medicine, 16(9), 606-613. https://doi.org/10.1046/j.1525-1497.2001.016009606.X

La Guardia, J. G., Ryan, R. M., Couchman, C. E., \& Deci, E. L. (2000). Within-person variation in security of attachment: A self-determination theory perspective on attachment, need fulfillment, and well-being. Journal of Personality and Social Psychology, 79(3), 367. https://doi.org/10.1037//0022-3514.79.3.367

Larivière, V. (2012). On the shoulders of students? The contribution of PhD students to the advancement of knowledge. Scientometrics, 90(2), 463-481. https://doi.org/10.1007/s11192-011-0495-6

Levecque, K., Anseel, F., De Beuckelaer, A., Van der Heyden, J., \& Gisle, L. (2017). Work organization and mental health problems in PhD students. Research Policy, 46(4), 868-879. https://doi.org/10.1016/j.respol.2017.02.008

Lipson, S. K., Zhou, S., Wagner, B., III, Beck, K., \& Eisenberg, D. (2016). Major differences: Variations in undergraduate and graduate student mental health and treatment utilization across academic disciplines. Journal of College Student Psychotherapy, 30(1), 23-41. https://doi.org/10.1080/87568225.2016.1105657

Litalien, D., Guay, F., \& Morin, A. J. (2015). Motivation for PhD studies: Scale development and validation. Learning and Individual Differences, 41, 1-13. https://psycnet.apa.org/doi/10.1016/j.lindif.2015.05.006

Lonka, K., Ketonen, E., Vekkaila, J., Cerrato Lara, M., \& Pyhältö, K. (2019). Doctoral students' writing profiles and their relations to well-being and perceptions of the academic environment. Higher Education, 77(4), 587-602. https://doi.org/10.1007/s10734-018-0290-X

Lovibond, P. F., \& Lovibond, S. H. (1995). The structure of negative emotional states: Comparison of the Depression Anxiety Stress Scales (DASS) with the Beck Depression and Anxiety Inventories. Behaviour Research and Therapy, 33(3), 335-343. https://doi.org/10.1016/0005-7967(94)00075-u 
Lovitts, B. E. (2002). Leaving the ivory tower: The causes and consequences of departure from doctoral study: Rowman \& Littlefield Publishers.

Lovitts, B. E., \& Nelson, C. (2000). The hidden crisis in graduate education: Attrition from Ph. D. programs. Academe, 86(6), 44. http://dx.doi.org/10.2307/40251951

Lucas, R. E., Diener, E., \& Suh, E. (1996). Discriminant Validity of Well-Being Measures. Journal of Personality and Social Psychology, 71(3), 616-628. https://psycnet.apa.org/doi/10.1037/0022-3514.71.3.616

Lynch, M. F., Salikhova, N. R., \& Salikhova, A. B. (2018). Internal motivation among doctoral students: Contributions from the student and from the student's environment. International Journal of Doctoral Studies, 13, 255-272. https://doi.org/10.28945/4091

Marais, G. A. B., Shankland, R., Haag, P., Fiault, R., \& Juniper, B. (2018). A survey and a positive psychology intervention on French phd student well-being. International Journal of Doctoral Studies, 13, 109-138. https://doi.org/10.28945/3948

Martin, A., Rief, W., Klaiberg, A., \& Braehler, E. (2006). Validity of the brief patient health questionnaire mood scale (PHQ9) in the general population. General Hospital Psychiatry, 28(1), 71-77. https://doi.org/10.1016/j.genhosppsych.2005.07.003

Martinsuo, M., \& Turkulainen, V. (2011). Personal commitment, support and progress in doctoral studies. Studies in Higher Education, 36(1), 103-120. https://doi.org/10.1080/03075070903469598

Maslach, C., \& Jackson, S. E. (1981). The measurement of experienced burnout. Journal of Organizational Behavior, 2(2), 99-113. https://doi.org/10.1002/job.4030020205

Moate, R. M., Gnilka, P. B., West, E. M., \& Rice, K. G. (2019). Doctoral student perfectionism and emotional well-being. Measurement and Evaluation in Counseling and Development, 52(3), 145-155. https://doi.org/10.1080/07481756.2018.1547619

Oldham, G. R., \& Cummings, A. (1996). Employee creativity: Personal and contextual factors at work. Academy of Management Journal, 39(3), 607-634. https://psycnet.apa.org/doi/10.2307/256657

Overall, N. C., Deane, K. L., \& Peterson, E. R. (2011). Promoting doctoral students' research self-efficacy: Combining academic guidance with autonomy support. Higher Education Research \& Development, 30(6), 791-805. https://doi.org/10.1080/07294360.2010.535508

Palys, T. S., \& Little, B. R. (1983). Perceived life satisfaction and the organization of personal project systems. Journal of Personality and Social Psychology, 44(6), 1221. https://psycnet.apa.org/doi/10.1037/0022-3514.44.6.1221

Park, C. (2005). New Variant PhD: The changing nature of the doctorate in the UK. Journal of Higher Education Policy and Management, 27(2), 189-207. doi:10.1080/13600800500120068

Pavot, W., \& Diener, E. (2009). Review of the satisfaction with life scale. In Assessing well-being (pp. 101-117): Springer.

Pearson, M., Evans, T., \& Macauley, P. (2008). Growth and diversity in doctoral education: assessing the Australian experience. Higher Education, 55(3), 357-372. https://doi.org/10.1080/13600800500120068

Pychyl, T. A., \& Little, B. R. (1998). Dimensional specificity in the prediction of subjective well-being: Personal projects in pursuit of the PhD. Social Indicators Research, 45(1-3), 423-473. https://doi.org/10.1023/A:1006970504138

Pyhältö, K., \& Keskinen, J. (2012). Doctoral students' sense of relational agency in their scholarly communities. International Journal of Higher Education, 1(2).

Radloff, L. S. (1977). The CES-D scale: A self report depression scale for research in the general population. Applied Psychological Measurements, 1, 385-401.

Rummell, C. M. (2015). An exploratory study of psychology graduate student workload, health, and program satisfaction. Professional Psychology: Research and Practice, 46(6), 391-399. https://psycnet.apa.org/doi/10.1037/pro0000056

Ryan, R. M., \& Deci, E. L. (2000). Self-determination theory and the facilitation of intrinsic motivation, social development, and well-being. American Psychologist, 55(1), 68. https://psycnet.apa.org/doi/10.1037/0003-066X.55.1.68

Ryff, C. D. (1989). Happiness is everything, or is it? Explorations on the meaning of psychological well-being. Journal of Personality and Social Psychology, 57(6), 1069. https://psycnet.apa.org/doi/10.1037/0022-3514.57.6.1069

Ryff, C. D., \& Keyes, C. L. (1995). The structure of psychological well-being revisited. Journal of Personality and Social Psychology, 69(4), 719-727. https://doi.org/10.1037//0022-3514.69.4.719

Schmidt, M., \& Hansson, E. (2018). Doctoral students' well-being: A literature review. International Journal of Qualitative Studies on Health and Well-being, 13(1), 1508171. https://doi.org/10.1080/17482631.2018.1508171

Schmidt, M., \& Umans, T. (2014). Experiences of well-being among female doctoral students in Sweden. International Journal of Qualitative Studies on Health and Well-being, 9(1), 23059. https://doi.org/10.3402/qhw.v9.23059

Seligman, M. (2011). Flourish: A Visionary New Understanding of Happiness and Well-being. Free Press. 
Serrão, C., \& Alves, S. (2019). Effects of mindfulness-based cognitive therapy on a group of postgraduate students: An exploratory study. Alternative and Complementary Therapies, 25(1), 37-42. https://doi.org/10.1089/act.2018.29206.cse

Stamp, E., Crust, L., Swann, C., Perry, J., Clough, P., \& Marchant, D. (2015). Relationships between mental toughness and psychological wellbeing in undergraduate students. Personality and Individual Differences, 75, 170-174. https://psycnet.apa.org/doi/10.1016/j.paid.2014.11.038

Stecker, T. (2004). Well-being in an academic environment. Medical Education, 38(5), 465-478. https://doi.org/10.1046/j.1365-2929.2004.01812.x

Stubb, J., Pyhältö, K., \& Lonka, K. (2011). Balancing between inspiration and exhaustion: PhD students' experienced sociopsychological well-being. Studies in Continuing Education, 33(1), 33-50. https://doi.org/10.1080/0158037X.2010.515572

Stubb, J., Pyhältö, K., \& Lonka, K. (2012). The experienced meaning of working with a PhD thesis. Scandinavian Journal of Educational Research, 56(4), 439-456. http://dx.doi.org/10.1080/00313831.2011.599422

Sverdlik, A., \& Hall, N. C. (2019). Not just a phase: Exploring the role of program stage on well-being and motivation in doctoral students. Journal of Adult and Continuing Education. https://doi.org/10.1177\%2F1477971419842887

Sverdlik, A., Hall, N. C., McAlpine, L., \& Hubbard, K. (2018). The PhD experience: A review of the factors influencing doctoral students' completion, achievement, and well-being. International Journal of Doctoral Studies, 13, 361-388. https://doi.org/10.28945/4113

Tennant, R., Hiller, L., Fishwick, R., Platt, S., Joseph, S., Weich, S., . . Stewart-Brown, S. (2007). The Warwick-Edinburgh mental well-being scale (WEMWBS): development and UK validation. Health and Quality of life Outcomes, 5(1), 63.

Watson, D., Clark, L. A., \& Tellegen, A. (1988). Development and validation of brief measures of positive and negative affect: the PANAS scales. Journal of Personality and Social Psychology, 54(6), 1063. https://doi.org/10.1037/00223514.54.6.1063

Weinstein, N., Przybylski, A. K., \& Ryan, R. M. (2012). The index of autonomous functioning: Development of a scale of human autonomy. Journal of Research in Personality, 46(4), 397-413. https://psycnet.apa.org/doi/10.1016/j.jrp.2012.03.007

Westerhof, G. J., \& Keyes, C. L. (2010). Mental illness and mental health: The two continua model across the lifespan. Journal of Adult Development, 17(2), 110-119. https://doi.org/10.1007/s10804-009-9082-y

Winefield, H. R., Goldney, R. D., Winefield, A. H., \& Tiggemann, M. (1989). The General Health Questionnaire: Reliability and validity for Australian youth. Australian and New Zealand Journal of Psychiatry, 23(1), 53-58.

World Health Organisation. (2014). Mental health: A state of well-being. Retrieved from https://www.who.int/features/factfiles/mental_health/en/

Yaghubi, H., Karimi, H., Omidi, A., Barouti, E., \& Abedi, M. (2012). Validity and factor structure of the General Health Questionnaire (GHQ-12) in university students. International Journal of Behavioral Sciences; 6(2), 153-160. Retrieved from http://www.behavsci.ir/article_67775.html

Yoon, S., Lee, Y., Han, C., Pae, C.-U., Yoon, H.-K., Patkar, A. A., . . Kim, Y.-K. (2014). Usefulness of the patient health Questionnaire-9 for Korean medical students. Academic Psychiatry, 38(6), 661-667. https://doi.org/10.1007/s40596-014$\underline{0140-9}$

Zahl, S. B. (2013). The role of community for part-time doctoral students: Exploring how relationships support student persistence. (3587513 Ph.D.) Indiana University.

Zahniser, E., Rupert, P. A., \& Dorociak, K. E. (2017). Self-care in clinical psychology graduate training. Training and Education in Professional Psychology, 11(4), 283-289. https://psycnet.apa.org/doi/10.1037/tep0000172

Please cite this article as:

Scott, H., \& Takarangi, M.K.T. (2019). Measuring PhD students' well-being: Are we seeing the whole picture? Student Success, 10(3), 14-24. https://doi.org/10.5204/ssj.v10i3.1294

This article has been peer reviewed and accepted for publication in Student Success. Please see the Editorial Policies under the 'About' section of the Journal website for further information.

(c) (1) This work is licensed under a Creative Commons Attribution 4.0 International Licence. As an open access journal, articles are free to use with proper attribution. ISSN: 2205-0795 